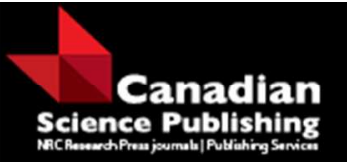

Canadian Journal of Forest Research Revue canadienne de recherche forestière

\title{
Barriers to enhanced and integrated climate change adaptation and mitigation in Canadian forest management
}

\begin{tabular}{|r|l|}
\hline Journal: & Canadian Journal of Forest Research \\
\hline Manuscript ID & cjfr-2017-0252.R1 \\
\hline Date Submitted by the Author: & 12-Sep-2017 \\
\hline Complete List of Authors: & $\begin{array}{l}\text { Williamson, Tim; Northern Forest Research Ctr., ; } \\
\text { Nelson, Harry; University of British Columbia, Forest Resources } \\
\text { Management }\end{array}$ \\
\hline $\begin{array}{r}\text { Is the invited manuscript for } \\
\text { consideration in a Special } \\
\text { Issue? : }\end{array}$ & $\begin{array}{l}\text { climate change, sustainable forest management, adaptation/mitigation } \\
\text { integration, mainstreaming, barriers }\end{array}$ \\
\hline & \\
\hline
\end{tabular}

SCHOLARONE ${ }^{\text {m }}$

Manuscripts 
Barriers to enhanced and integrated climate change adaptation and mitigation in Canadian forest management

Tim B. Williamson ${ }^{\mathrm{a},}$, Harry W. Nelson ${ }^{\mathrm{b}}$

${ }^{a}$ Natural Resources Canada, Canadian Forest Service, 5320-122 St., Edmonton, Alberta, T6H 3S5, Canada; tim.williamson@canada.ca

${ }^{b}$ Faculty of Forestry, University of British Columbia, Vancouver, BC, Canada; harry.nelson@ubc.ca 
Abstract:

Forests are sensitive to the effects of climate change and they play a significant role in carbon cycles. This duality has important implications for forest management in terms of requirements for enhanced and integrated adaptation and mitigation interventions. Two ideal conceptual level changes could provide the means for implementation. First, the incorporation of climate change considerations into definitions of sustainable forest management (SFM) would provide mandates for enhanced approaches. Second, the mainstreaming of enhanced SFM would facilitate implementation. There are, however, factors that may impede implementation. Identifying and evaluating these factors informs our understanding of requirements for adaptation/mitigation mainstreaming. This study reviews, organizes, and interprets the literature for the purposes of identifying and evaluating potential impediments. Harmonization barriers pertain to differences between adaptation and mitigation in pre-existing frames and beliefs. Enabling barriers are psychological and institutional in nature. Implementation barriers include capacity deficits (e.g., funding limits, science and knowledge deficits regarding benefits, trade-offs, and synergies between adaptation and mitigation) and governance issues. Barriers are interrelated, dynamic, and subjective. Addressing barriers requires a holistic approach that recognizes the complex and dynamic nature of forest management policy change processes.

52 Keywords: Climate change, sustainable forest management, adaptation / mitigation integration, mainstreaming barriers 
54

55

56

57

\section{Introduction}

The purpose of this review manuscript is to identify barriers to comprehensive and integrated climate change adaptation and mitigation in Canadian forest management. In its strategy document A vision for Canada's forests:2008 and beyond the Canadian Council of Forest Ministers (CCFM) stated: "consideration of climate change and climate variability is needed in all aspects of sustainable forest management." (CCFM 2008). We begin, therefore, with the normative view that in the context of climate change, one of the long-term goals of forest policy in Canada is to develop and implement a comprehensive and integrated response that incorporates, enhances, and integrates both adaptation and mitigation. However, climate change is a relatively new, unprecedented, and complex issue in forest management. Progress in developing and implementing adaptation and mitigation measures are in their early stages (Johnston et al. 2010; Gray 2012; Hoberg et al. 2016). Moreover, these measures are typically considered separately (Johnston et al. 2010; Keenan 2016). A logical first step in moving forward is to identify, evaluate, plan for, and where possible address barriers that may impede the development and implementation of comprehensive and integrated adaptation and mitigation (Moser and Ekstrom 2010).

To date, the literature on adaptation and mitigation process has identified a number of capacity requirements and barriers to either adaptation or mitigation in the contexts of human management systems in general (Moser and Ekstrom 2010; Biesbroek et al. 2013; Eisenack et al. 2014) and in forest management systems in particular (Jantarasami et al. 2010; Nelson et al. 2016; Johnston and Hesseln 2012; Hoberg et al. 2016). To our knowledge, however, there are no studies that have explicitly considered potential barriers to the development and implementation of comprehensive and integrated adaptation and mitigation in Canadian forest management 
77 contexts. The goal of this paper, therefore, is to address this knowledge gap by reviewing,

78 interpreting, and structuring the current literature in order to provide a holistic overview of

79 potential barriers to comprehensive and integrated adaptation/mitigation in Canadian forest

80 management.

\section{Concepts and definitions}

82 There is growing evidence and analysis regarding the current and potential future effects of

83 climate change on forest ecosystems and of requirements to adapt forest management to

84 maximize benefits and reduce negative impacts (Spittlehouse 2005; Lempriere et al. 2008;

85 Johnston et al. 2009; Seppälä et al. 2009; Williamson et al. 2009; Edwards and Hirsch 2012;

86 Price et al. 2013; Peterson et al. 2014; Keenan 2015). Adaptation is defined as: "adjustments in

87 natural or human systems in response to actual or expected climatic stimuli or their effects,

88 which moderates harm or exploits beneficial opportunities" (Edwards et al. 2015). The benefits

89 of adaptation in forest management include the potential to reduce impacts to both traditional

90 forest management values and objectives as well as to a host of new societal and community-

91 related impacts including water regulation and quality, soil erosion, public safety issues (e.g.,

92 reducing wildfire risk), and impacts on aquatic and terrestrial habitats. A variety of adaptations in

93 forest management have been suggested (Spittlehouse 2005; Millar et al. 2007; Ogden and Innes

94 2007a; Seppälä et al. 2009; Williamson et al. 2009; Johnston et al. 2009; Johnston et al. 2010;

95 Peterson et al. 2011; Gauthier et al. 2014; Le Goff and Bergeron 2014; Peterson et al. 2014). In

96 general these findings suggest a requirement for a comprehensive and multifaceted approach to

97 adaptation in forest management.

There is also broad recognition of the role of forest management in supporting climate

99 change mitigation (Nabuurs et al. 2007; CCFM 2009; Carlson et al. 2010; Golden et al. 2011; 
100 Lemprière et al. 2013; Smyth et al. 2014; FAO 2016; Hoberg et al. 2016; Lempriere et al. 2017).

101 In the context of forest management, mitigation refers to measures or actions that reduce the 102 release of carbon from forest carbon stocks (e.g., reducing deforestation), that increase the 103 carbon capture and sink potential of forests (i.e., increasing carbon sequestration and forest 104 carbon stocks through afforestation or other forest management actions), and that promote the 105 substitution of wood products (including bioenergy) for products that are more emissions106 intensive on a life-cycle basis (Lemprière et al. 2013; Smyth et al. 2014; FAO 2016). A number

107 of forest based mitigation actions and strategies have been proposed for Canadian forest 108 management (Carlson et al. 2010; Golden et al. 2011; Metsaranta et al. 2011; Colombo et al. 109 2012; Lempriere et al. 2013; Smyth et al. 2014; Xu et al. 2017; Lempriere et al. 2017). A number 110 of studies have also looked at the economics of forest carbon strategies in Canada (McKenney et 111 al. 2004; Man et al. 2015; Kennedy et al. 2007).

112 In the broader arena of climate change policy, adaptation and mitigation are often 113 considered and addressed independently (Tol 2005; Biesbroek et al. 2009; Berry et al. 2015).

114 The same independence of approach has occurred in Canadian forest management (Johnston et 115 al. 2010). Adaptation and mitigation in forest management, however, are not mutually exclusive 116 (Innes et al. 2009; Keenan 2015; Keenan 2016). There are trade-offs, synergies, and interactions 117 between adaptation and mitigation in forest management (D'Amato et al. 2011; Metsaranta et al. 118 2011). For example, climate change could increase risks to forest carbon and reduce the benefits 119 of forest carbon mitigation over time (Metsaranta et al. 2011). Adaptation measures within forest 120 management may reduce the risks to mitigation and enhance the permanence of mitigation 121 investments (Locatelli et al. 2011). 
Various studies have suggested that integration and coordination of adaptation and

123

124

125

126

127

128

129

130

131

132

133

134

135

136

137

138

139

140

141

142

143

144

mitigation in forest management is logical if not necessary for ensuring appropriate climate responses (Millar et al. 2007; Ravindranath 2007; Collaborative Partnership on Forests 2008;

Guariguata et al. 2008; Buck et al. 2009; Innes et al. 2009; Klenk et al. 2011; Locatelli et al. 2011; D’Amato et al. 2011; Kant and Wu 2012; FAO 2013; Wang and McCarl 2013; Millar et

al. 2014; Smith et al. 2014; Berry et al. 2015; Keenan 2015; Locatelli et al. 2015; Keenan 2016).

There are a variety of motivations and reasons for integration. Integration results in more efficient and more cost-effective climate change interventions (Duguma et al. 2014). Locatelli et al. (2015) noted that, depending on how they are implemented, mitigation projects can either facilitate or hinder adaptation. For example, investments in mitigation (that ignore adaptation) can potentially crowd out investments in adaptation. Similarly, adaptation projects, if evaluated or implemented without consideration of mitigation, can restrict mitigation opportunities or may reduce the carbon benefits of previously implemented mitigation projects. From an economics perspective, the underlying costs and benefits associated with modifying regeneration, timber harvest, or timber rotation in anticipation of climate effects on productivity or disturbance risk may be quite different depending on whether carbon costs and benefits are included or excluded (Wang and McCarl 2013).

As noted the goal of this study is to provide an overview of potential barriers to the development and implementation of comprehensive and integrated adaptation/mitigation in Canadian forest management. Following Moser and Ekstrom (2010), barriers are considered to be impediments and capacity deficits that can "stop, delay, or divert" the development and implementation of comprehensive and integrated adaptation/mitigation. Comprehensive and integrated adaptation/mitigation is considered to be an ideal state of being where Canadian 
145 forest management policies, practices, and investments support the identification and

146 implementation of economically rational, and technically feasible adaptation and mitigation

147 measures where interactions, synergies, trade-offs, and interrelationships between adaptation and 148 mitigation have been fully considered.

149 Approach

150 This review follows what Eisenack et al. (2014) describe as a positive (i.e., descriptive or 151 explanatory) approach for barriers analysis. Following this approach an ultimate outcome is

152 specified precisely, the means necessary for implementation are identified, and the reasons why 153 the means are not being implemented (i.e., barriers) are identified and evaluated. The following 154 section provides a more detailed description of the ideal outcome and the means of 155 implementation.

The second part of this manuscript reviews, synthesizes, and structures the literature on

157 adaptation and mitigation barriers in Canadian forest management systems in order to identify

158 and evaluate potential barriers to developing and implementing the conceptual ideal described in

159 the next section. Barriers are grouped into three broad categories: harmonization, enabling, and

160 implementation barriers. We consider this categorization as a way or organizing barriers to

161 developing and implementing the ideal outcome described in the next section.

162 An ideal outcome and means of implementation

The general context for this review is Canadian forest management. The majority of

164 forestland in Canada is retained in public ownership. Forestry related policies and regulations are 165 established and enforced by provincial governments. In general the goals of forest management 166 on crown lands are consistent with sustainable forest management principles. Canada's forest

167 industry obtains access rights to timber on public lands through various kinds of tenure 
168

169

170

171

172

173

174

175

176

177

178

179

180

181

182

183

184

185

186

187

188

189

arrangements that require them to fulfill certain management obligations that ensure that forests are managed in a manner consistent with public forest policies and regulations.

Sustainable forest management (SFM) is the basis for many forest policies in Canada (CCFM 2008). It is a holistic approach to forest management that considers the economic, social, and environmental benefits of forests and the importance of maintaining natural capital and ecological processes for the purpose of preserving forest goods and services in perpetuity.

Sustainable forest management as a concept provides a possible frame for comprehensive and integrated adaptation/mitigation (Spittlehouse 2005; Collaborative Partnership on Forests 2008;

Seppälä et al. 2009; Edwards and Hirsch 2012; Gray 2012; Steenberg et al. 2013; Klenk et al. 2015). In some cases, current SFM standards may already support aspects of both adaptation and mitigation (e.g., maintaining biodiversity, recognizing the role of forests in global ecological cycles) (FAO 2013; Klenk et al. 2015).

Although SFM potentially provides the necessary enabling frame for comprehensive and integrated adaptation/mitigation, modifications to current SFM standards are needed because current versions of SFM tend not to be sufficiently explicit in terms of recognizing climate change and the linkages between adaptation and mitigation (Steenberg et al. 2013; Williamson and Edwards 2014; Keenan 2015). Therefore, modified forms of SFM that recognize opportunities and requirements for both adaptation and mitigation and their interrelationships are needed (Williamson and Edwards 2014; Klenk et al. 2015).

Presuming the existence of SFM standards that account for climate change and that enable comprehensive and integrated adaptation/mitigation, the question then becomes one of determining how to implement such a standard. Various papers have proposed structured 
190 decision-making or mainstreaming approaches for incorporating adaptation considerations into 191 decision making in general and forest management in particular (Ohlson et al. 2005; Nitschke 192 and Innes 2008; Ogden and Innes 2009; Johnston et al. 2010; Peterson et al. 2011; FAO 2013;

193 Edwards et al. 2015; Wamsler 2015; Pasquini et al. 2015). Guariguata et al. (2008) and Locatelli 194 et al. (2015) identified mainstreaming as a potential way of incorporating both adaptation and 195 mitigation into forest management (however these authors also suggested that there are a number 196 of reasons for mainstreaming adaptation and mitigation separately).

Mainstreaming is the incorporation of climate change considerations into all aspects of forest management policies, programs, plans, and practices on a regular and ongoing basis 199 (Cowling et al. 2008; Williamson et al. 2012). A mainstreaming approach to climate change adaptation based on a third-generation vulnerability assessment methodology was first described by Fussel and Klein (2006). The Canadian Council of Forest Ministers (CCFM) modified this approach for application to Canadian forest management (Williamson et al. 2012; Edwards et al. 2015). Mainstreaming, as described in recent CCFM work, is a process that combines structured decision-making and adaptive management approaches (Williamson et al. 2012; Edwards et al. 2015). The CCFM mainstreaming approach does not specifically include mitigation but it could

206 be expanded to do so. Mainstreaming would support the ability to account for trade-offs, to 207 address uncertainty, and to manage adaptively by promoting a continuous process of selecting 208 and implementing options, evaluating, and modifying where justified.

\section{Types of barriers}

As noted, the goal of this review is to identify potential barriers to developing and

211 implementing the ideal outcome described in the previous section. We group barriers into three 212 categories based on their similarities, differences, and resemblances and based on how they 
213 pertain to particular aspects of adaptation/mitigation mainstreaming (Table 1). The barrier types

214 (harmonization, enabling, and implementation) are defined as follows.

Harmonization barriers are defined as pre-existing frames and beliefs about adaptation

216 and mitigation that promote the continued consideration of adaptation and mitigation as

217 independent responses to climate change. Harmonization barriers result from biases to, and or

218 preferences for, either mitigation or adaptation on the part of agents or to a tendency to view

219 these as independent and unrelated climate responses. The effect of harmonization barriers is an

220 inability or significant challenges in agreeing on integrated adaptation and mitigation as a forest

221 management goal. Thus, in the presence of significant harmonization barriers, the ability to

222 address enabling and implementation barriers may be constrained. Harmonization barriers are, in

223 some respects, unique to integration aspects of adaptation and mitigation. Enabling and

224 implementation barriers can exist for adaptation or mitigation independently or to joint

225 adaptation/mitigation.

226 Enabling factors are those that empower, motivate, or provide incentive for the pursuit of

227 comprehensive and integrated mainstreaming. Enabling barriers, therefore, are defined as the

228 absence of factors that are required to empower, motivate, or incentivize comprehensive and

229 integrated mainstreaming approaches. The effect of enabling barriers is that there is no

230 motivation or incentive for adopting integrated mainstreaming. There may, in fact, be penalties

231 or sanctions associated with proceeding with this approach.

232 Implementation barriers are factors that are to some degree incremental to harmonization or

233 enabling barriers. Implementation barriers are defined as absence (or insufficiency) of

234 resources, required knowledge, and or the means and mechanisms for implementation. The effect 
235 of implementation barriers is limited capacity for implementation, which is in addition to the 236 effects of harmonization and enabling barriers.

237 The following three sections describe and assess various harmonization, enabling, and 238 implementation barriers in more detail and provide strategies and options for addressing them.

239 There are, however, some overarching considerations about barriers in the literature that merit 240 noting. The first is that barriers are interrelated and that actions to address barriers individually 241 will not necessarily be effective (Eisenack et al. 2014). Eisenack et al. (2014) refer to "dynamic 242 webs of barriers" suggesting the need for comprehensive assessment approaches and 243 comprehensive strategies for addressing barriers. The barriers discussed in the following sections 244 are to varying degrees structural, interrelated, dynamic, and ubiquitous. Some barriers are "actor 245 centered" and others are embedded in the "system of interest" (Eisenack et al. 2014). These 246 features have implications for how and why barriers emerge and for how they may be addressed.

247 The degree to which specific barriers or clusters of barriers are mutable varies. In some cases 248 reducing barriers requires system transformations, which often are the result of longer term, 249 multi-scale processes of social learning and policy reform.

\section{Harmonization barriers}

251 Although there are rational arguments for an integrated approach to adaptation and mitigation 252 in forestry, significant challenges may arise because of ambivalence, resistance, or opposition to 253 proceeding with such an approach on the part of key forestry decision-makers and agents. This 254 may, to some extent, be attributable to differences between adaptation and mitigation among 255 forest management agents in beliefs, framing, knowledge, and awareness (Locatelli et al. 2015; 256 Keenan 2016). Moser (2012) refers to these differences as "disharmonious discontents." 
Adaptation is a recent addition to the discourse on climate change in forestry, and it has

258 received less attention than mitigation (Johnston et al. 2010; Keskitalo 2011; Keenan 2016). Mitigation in forestry has a longer history (at least in terms of discussion and analysis of deforestation issues and mitigation opportunities; see, for example, Sedjo and Solomon (1989)). Independence of analysis and discourse on adaptation and mitigation can result in differences in beliefs, as well as greater awareness and understanding of, and stronger support for, one area over another, on the part of influential forestry decision-makers.

Keenan (2016) suggests that adaptation and mitigation in forest management are not on an equal footing. The question then arises: how can attitudinal differences within a particular forest management community be mediated. Under the right conditions, and despite significant challenges, forest management is a sector with some potential to address the various barriers that stand in the way of harmonizing adaptation and mitigation (Buck et al. 2009; Innes et al. 2009; Roberts et al. 2009). Forest management activities can address both adaptation and mitigation and their integration may be more feasible in cases involving a homogeneous group of agents within similar institutional contexts operating under similar norms and principles of management (Thuy et al. 2014).

As noted, factors contributing to differences in attitudes, frames, beliefs and support for adaptation and mitigation generally manifest as ambivalence, resistance, or opposition to integration. These tend to be, therefore, barriers to even initial consideration of comprehensive and integrated adaptation and mitigation in forest management. These barriers may diminish over time as social learning about the merits of integration occurs. However, the completion of integrated research and analysis about adaptation/mitigation strategies and information sharing and dialogue about what a comprehensive and integrated approach to climate change in forest 
280

281

282

283

284

285

286

287

288

289

290

291

292

293

294

295

296

297

298

299

300

301

302

management might look like and how it would be implemented would help to mediate differences in support for adaptation and mitigation. Locatelli et al. (2011) suggested that processes allowing individuals engaged in forest mitigation activities to become informed about adaptation and vice versa improve the prospects of integration (note this also pertains to the presence of harmonization barriers noted earlier). Participants from both groups could be educated about the rationales for each activity and trained in the other group's tools and methods.

\section{Enabling barriers}

Enabling barriers exist where agents are not empowered, they are not motivated, there is a lack of incentives, or there are penalties associated with adaptation/mitigation mainstreaming. Enabling barriers for comprehensive and integrated adaptation/mitigation can result from enabling barriers to adaptation or mitigation or enabling barriers to joint implementation. Psychological factors

Psychological factors such as cognitive bias and perception bias have the potential to affect judgements related to the salience of issues, and the need for comprehensive and integrated responses to climate change in forest management. Cognitive biases result in departures from rational or justifiable choices. One example of a cognitive bias is "status quo bias" (Kahneman et al. 1991). In their behavioral experiments, Samuelson and Zeckhauser (1988) found a strong preference for the status quo (i.e., maintain current status by sticking with previous choices or doing nothing). Various explanations for this behavior are possible, including loss aversion, sunk cost thinking, and the need to feel in control. Kahneman and Tversky (1982) suggested that preference for the status quo may be attributable to feelings of regret associated with potential bad outcomes from change outweighing feelings of regret associated with bad outcomes from inaction. The connections to mainstreaming of adaptation/mitigation 
303 304 305 306

307

mainstreaming are clear. Status quo bias has the potential to reduce the motivation of forestry agents for adaptation/mitigation mainstreaming. Overcoming status quo bias may require evidence that the potential bad outcomes (or potential net benefits) of the status quo are disproportionally worse than the potential bad outcomes (or potential net benefits) associated with new approaches.

In the context of forest management, perceptions about climate change risks to forests and forest values directly influences the willingness of forest management agents to consider adaptation (Davidson et al. 2003). Several studies have evaluated the degree to which Canadian forest managers are concerned about climate change and whether they are prepared to consider adaptation. Many studies have found that generally individual forest managers, professionals, and forest experts in Canada are concerned about climate change and generally support adaptation (Williamson et al. 2005; Colombo 2006; Johnston et al. 2010; Johnston and Hesseln 2012; Morin 2015; Nelson et al. 2016).

The studies noted above suggest that general perceptions about climate change risks are not a significant barrier to adaptation. The level of support on the part of forest managers for adaptation may be attributable to significant education efforts in Canadian forestry about climate change impacts and adaptation requirements over the last number of years (Table 2).

As opposed to mitigation and adaptation, comprehensive and integrated adaptation/mitigation is currently not at the forefront of conversations about climate change in Canadian forest management. One can speculate that in addition to cognitive bias, there may currently be a relatively low degree of concern about the lack of consideration of this approach in Canadian forest management. This may translate into passive (or lack of) support for adaptation/mitigation mainstreaming. As was the case for adaptation, developing support for 
326 comprehensive and integrated adaptation/mitigation may require new information regarding the

327 relative merits, costs, and risks of this approach and significant effort to raise awareness and

328 engage in conversations with forest management stakeholders about how to develop and

329 implement the approach.

$330 \quad$ Institutions

331 Forest management institutions include laws, policies, tenure arrangements, codes of 332 conduct, behavioral norms, rules, penalties, and forest management standards. They provide 333 incentives for, and enable actions, and they penalize unacceptable behaviours and decisions. 334 Institutions are therefore central to the capacity and effectiveness of forest management systems 335 in adapting to and mitigating climate change (Williamson and Isaac 2013). Forest management 336 institutions that have not incorporated climate change are a barrier to adaptation and to 337 mitigation in Canadian forest management (Klenk et al. 2011; Johnston and Hesseln 2012;

338 Hoberg et al. 2016) and, therefore, by extension to comprehensive and integrated adaptation and 339 mitigation.

340 Currently forest management institutions in Canada do not consider climate change to the 341 degree necessary for enabling effective climate response (Spittlehouse 2005; Johnston et al. 342 2010; Klenk et al. 2011; Greig and Bull 2011; Johnston and Hesseln 2012; Rayner 2012;

343 Steenberg et al. 2013; Nelson et al. 2016; Hoberg et al. 2016). This situation creates a dilemma 344 for the mainstreaming of adaptation and mitigation, because institutions that do not consider 345 climate change or that do not link adaptation and mitigation in policy contexts pose direct 346 barriers to integrated adaptation and mitigation action (Locatelli et al. 2011).

347 Institutional barriers to comprehensive and integrated adaptation/mitigation can be grouped 348 into two broad types. The first type of barrier is absence of policy regimes that recognize climate 
349 change, that support and enable adaptation and mitigation, and that link adaptation and

350 mitigation (Spittlehouse 2005; Collaborative Partnership on Forests 2008; Johnston et al. 2010;

351 Locatelli et al. 2011; Golden et al. 2011; Greig and Bull 2011; Steenberg et al. 2014; Keenan

352 2015; Keenan 2016; Hoberg et al. 2016). The second type of barrier pertains to institutions that

353 are ill equipped to address the increasingly complex, dynamic, and uncertain decision

354 environments associated with climate change (Ogden and Innes 2007a; Millar et al. 2007; Joyce

355 et al. 2009; Seppälä et al. 2009; Innes et al. 2009; Williamson et al. 2009; Klenk et al. 2011;

356 Johnston and Hesseln 2012; Gray 2012). Institutions that are forward looking, that enable

357 collaborative adaptive management, that promote flexible approaches that are reversible as new

358 information becomes available, that promote learning, and that allow for diversity of approaches

359 that can be tailored to different local circumstances and modified over time are called for (Millar

360 et al. 2007; Ogden and Innes 2009; Klenk 2011; Gray 2012).

361 A particular aspect of the Canadian forest management institutional context is the potential

362 for differences in incentives and costs of adaptation between private agents operating on crown

363 forest lands and provincial governments. In Canada, various kinds of tenure arrangements

364 provide the basis for transferring rights to harvest timber on crown land. Forest industry tenures

365 "specify the rights, obligations, and duration of the tenure agreement as well as how the tenure

366 will be administered (Hoberg et al. 2016, pg 77). Hotte et al. (2016) notes that differences in the

367 distribution of costs and benefits of some adaptation measures between private agents and public

368 management agencies can be a barrier to action (the "principal-agent problem"). They note that

369 explicit analysis of the incentives and disincentives facing private sector interests on crown land

370 and public forestland managers may be required in order to identify and address barriers to

371 adaptation. The principal-agent problem also pertains to forest carbon mitigation. Hoberg et al. 
372 (2016) note that in British Columbia, including carbon in tenure, and expanding the duration of

373 tenures would provide a stronger incentive for tenure holders to manage for carbon as well as

374 timber values.

375 Overcoming institutional barriers will be challenging. It may require overcoming

376 "longstanding and sometimes hard-won standardized practices and deeply ingrained rules of

377 thumb." Kates et al (2012, pg 7159) and it may require different policy learning types (e.g.,

378 government, social) for different learning outcomes (e.g., organization change, paradigm change)

379 (Bennett and Howlett 1992). An important initial step is to undertake assessments and analysis

380 that illustrate the costs and risks of inaction, that demonstrate the benefits of change, and that

381 identify options for moving forward (Edwards et al. 2015). In terms of comprehensive and

382 integrated adaptation/mitigation, this type of analysis is not currently available. Beyond the

383 development of basic new knowledge, it should be also be acknowledged that there are

384 significant knowledge gaps about the organic nature of policy and institutional change processes

385 in forestry. There is, therefore, also a need for research into governance and policy change

386 processes. This is required in order to provide a realistic understanding of factors that affect

387 policy change processes and about how to mobilize policy change processes in order to support

388 comprehensive and integrated adaptation/mitigation (Klenk et al. 2011).

$389 \quad$ Leadership

390 Experimentation, innovation, and change can occur at many different levels. Leadership

391 usually plays a significant role in supporting experimentation, innovation, and change at these

392 various levels. Cumulative learnings obtained through experimentation, innovation, and change

393 at multiple levels leads to higher-level system wide changes (Pahl Wostl 2009). There are many

394 different kinds of leadership. Political leadership and political will is required for higher-level 
395 policy change at legislative levels and for the establishment of inter-jurisdictional collaborations.

396 Organizational leadership (e.g. senior managers in organizations) is required for enabling mid-

397 level adaptations and for promoting innovative approaches to management within the context of

398 existing laws and policies. Collaborative leaders are individuals who have the ability to bring

399 together people from diverse backgrounds to address issues and challenges of common interest.

400 Various studies in Canada have noted the importance of leadership in addressing climate

401 change in Canadian forestry. Gray (2012, pg 12) notes: "The ability of an organization to

402 manage for climate change depends not only on how its staff and partners are marshalled and

403 organized to work together, but also on its leadership." Leadership can be important for the

404 adoption of innovative approaches at local scales. In a review of forest sector based vulnerability

405 case studies across Canada, Johnston and Edwards (2013) noted that a significant factor in the

406 successful completion of the studies was the presence of local champion who provided an

407 essential bridge between local stakeholders and outside experts involved in the technical

408 analysis. Van Damme et al. (2008) identified the significant contribution of corporate leadership

409 at Millar Western (a forest company in west-central Alberta) in promoting a culture that values

410 and promotes "family, productivity, innovation, integrity, and social responsibility," Millar

411 Western was one of the first companies in Canada to incorporate climate change considerations

412 into their long run forest management planning process.

413 Leadership is also important at provincial and national scales. Canada's forest ministers

414 provided significant leadership in identifying climate change as one of two issues of national

415 importance in its strategic document "Vision for Canada's forests:2008 and beyond." In 2010,

416 Canada's provincial and territorial premiers asked their forestry ministers to collaborate with the

417 federal government to assess the vulnerability of Canada's tree species to climate, to identify 
418 adaptation options, and to develop tools to support forest managers in incorporating climate 419 change into forest management (Edwards and Hirsch 2012).

420 A lack of leadership support or a lack of political will can be an important barrier to 421 responding to climate change (Norman 2008; Ford et al. 2011; Ford and King 2015). Moser and 422 Ekstrom (2010) noted that leadership is important at all stages of adaptation mainstreaming, 423 particularly in the early stages, when there are no laws, mandates, or public demands, but also 424 over the longer term, for sustaining attention and focus. A potential absence of leadership 425 support for mainstreaming of integrated adaptation and mitigation or lags in supporting changes 426 in approach is an impediment. For example, Klenk et al. (2011,pg 353) note that "without 427 political will and a social licence to legitimize proactive, experimental, adaptive collaborative 428 management, prospects of implementing flexible policies to mitigate and adapt to climate change 429 within sustainable forest management are low." As previously noted, differences in perceptions, 430 differences in how policy makers frame adaptation and mitigation, or simply their tendency to 431 prefer the status quo over significant change (as discussed previously) could affect the 432 willingness of leaders to support comprehensive and integrated adaptation/mitigation. In the 433 specific context of Canadian forestry policy, forestry leaders are currently facing an array of 434 competing issues, including increasing competitive pressures on Canada's forest industry, 435 diminishing resources for many aspects of forest management, urbanization, changes in societies 436 expectations about forest values (Johnston and Hesseln 2012; Rayner 2012). These issues 437 influence their willingness to introduce and champion novel, complex, untested modifications 438 that have long-term time horizons and uncertain outcomes.

439 Processes designed to integrate science and policy can make a significant difference relative 440 to ensuring policy relevant research and influencing policy leaders. Prescott and Weese (2014) 
441 describe an eight-step process developed in British Columbia, Canada, for science policy

442 integration on climate change adaptation in BC forest management. This process was used to

443 identify and prioritize policy relevant research in support of adapting BC's forest management

444 framework to address climate change.

445 Implementation barriers

446 For the purpose of this review, implementation barriers refer to deficits or inadequacies in

447 funding, knowledge, governance, and in assessment and monitoring capacity. Overcoming

448 implementation barriers requires enhancements in the capacity of forest management systems to

449 develop and implement comprehensive and integrated mainstreaming approaches. Similar to

450 enabling barriers, implementation barriers to comprehensive and integrated adaptation/mitigation

451 may be a result of adaptation or mitigation barriers, or joint barriers.

452 Governance

453 Current forest management governance regimes are ill-equipped to handle the enhanced 454 policy requirements associated with adaptation and mitigation (Rayner 2012; Lindahl et al. 2017;

455 Timberlake and Schultz 2017)). Governance issues pertain to both policy capacity (Rayner 2012)

456 and structural features (Gray 2012; Hoberg et al. 2016). Pettersson and Keskitalo (2013) argued

457 that forest policy systems tend to be reactive and that modifying these systems in anticipation of

458 uncertain futures is difficult. Rayner (2012) examined forest management adaptation in the

459 context of a Canadian forest policy system and found disconnects between increasing policy

460 mandates associated with climate change and decreasing governance capacity. Reducing these

461 disconnects would contribute to the efficiency and effectiveness of responses to climate change

462 in Canadian forest policy. 
In terms of the structural aspects of governance, several authors have found that traditional modes of forest management governance (e.g., top-down, monocentric structures) may not have the necessary flexibility or responsiveness to deal with the complex, dynamic, spatially diverse, and uncertain features of climate change (Seppälä et al. 2009; Gray 2012; Timberlake and Schultz 2017). Effective implementation of mainstreaming for adaptation and mitigation requires the development of new hybrid forms of governance combining the advantages of centralized governance (coordination, stability, compliance) with those of more horizontal structures (flexibility, autonomy for local decision-making, multi-stakeholder engagement, comanagement) (Gray 2012). In many respects climate change impacts will be noticed first at local scales. Adaptation at local scales is dependent on local forest managers having the authority, mandate, knowledge, and autonomy to implement adaptations locally (Keenan 2015; Johnston et al. 2010). Nelson et al. (2016), however, note that forest management practitioners in BC feel they do not have sufficient authority to develop and implement local adaptation measures.

\section{Science and knowledge factors}

Climate change is unprecedented in forest management and it creates demands for new knowledge and scientific research (Millar et al. 2007; Lempriere et al. 2008; Klenk et al. 2011; Williamson et al. 2012; Lemprière et al. 2013; Keenan 2016; Nelson et al. 2016; Lawrence 2017). Uncertainty is greatest at local scales (i.e. scales most relevant to forest management decision-making) (Williamson et al. 2009; Johnston et al. 2010). Arguably, climate change makes obsolete that portion of scientific knowledge in forest management that has assumed a stationary climate. The combination of potential obsolete knowledge and new knowledge requirements results in knowledge gaps that act as barriers. There are four subcomponents to the science deficit problem as it relates to mainstreaming of adaptation and mitigation. First, there 
487 are knowledge gaps in assessing the impacts of climate change (including impacts on forest 488 carbon) and identifying suitable adaptation measures (Lemprière et al. 2008; Williamson et al. 489 2009; Johnston et al. 2009; Johnston et al. 2010). Second, there are knowledge gaps in assessing 490 forest carbon and identifying mitigation options under different biophysical, institutional, and 491 governance contexts (Greig and Bull 2011; Lemprière et al. 2013; Smyth et al. 2014). Specific 492 knowledge gaps pertain to permanence, leakage, monitoring of forest carbon over time, and 493 estimation of changes in forest carbon stocks (Nabuurs et al. 2007). Third, there are knowledge 494 gaps in terms of assessing synergies and trade-offs between adaptation and mitigation (Klein et 495 al. 2005; Ravindranath 2007; Golden et al. 2011; Lemprière et al. 2013; Lempriere et al. 2017).

496 Fourth, there are knowledge gaps about social transformation processes and about how to 497 overcome barriers to developing and implementing comprehensive and integrated adaptation / 498 mitigation (including institutional and governance barriers) given the reality of political/policy 499 change processes (Klenk et al. 2011).

$500 \quad$ Knowledge gaps are partly a result of the current funding of adaptation and mitigation 501 science. However, adaptation researchers have also noted that addressing knowledge gaps 502 requires more than simply spending more money on traditional science. Reducing knowledge 503 gaps also requires transforming the ways in which knowledge is created, accessed, and 504 information disseminated (Klenk et al. 2011; Gray 2012; Blades et al. 2016), Proposed options 505 for changing the way knowledge is produced and utilized include (1) establishing science 506 partnerships for joint knowledge production (Van Damme et al. 2008; Joyce et al. 2009; West et 507 al. 2009; Klenk et al. 2011; Peterson et al. 2011; Littell et al. 2012; Guariguata et al. 2012;

508 Prescott and Weese 2014; Keenan 2015; Keenan 2016); and (2) nurturing learning cultures (e.g., 509 adaptive comanagement) within forest management systems to promote adaptability and 
510 perpetual learning (Millar et al. 2007; Innes et al. 2009; Pahl Wostl 2009; Klenk et al. 2011;

511 Keenan 2015).

512 Knowledge exchange, information, education, and training

513 Although education efforts (Table 2) have been effective in increasing awareness and 514 understanding of climate change risks, there remains an issue related to levels of technical 515 knowledge and expertise required to support the development of practical adaptation and 516 mitigation strategies. A barrier that is often identified by forest managers is their own general 517 lack of specific understanding of climate modelling (including downscaling) and assessment 518 tools and techniques (e.g., vulnerability assessment, carbon budget models) (Williamson et al. 519 2005; Colombo 2006; Ogden and Innes 2007b; Nelson et al. 2016). These knowledge gaps make 520 it difficult for forest management practitioners to make decisions about climate change 521 adaptation and mitigation (Klenk et al. 2011).

522 A number of strategies have been proposed to address practitioner knowledge gaps.

523 Continued attention to traditional approaches to knowledge exchange such as workshops, 524 newsletters, and the development of communities of practice is necessary but not sufficient. The 525 development of user-friendly decision support tools and training in their use are needed to assist 526 managers in identifying options (Greig and Bull 2011; Edwards et al. 2015). There is also a need 527 to provide access to, or build technical capacity at local scales in the areas of climate modelling 528 and assessment (Klenk et al. 2011). Van Damme (2008) discusses an innovative approach where 529 the embedding of scientists in forest industry planning processes provides an effective model for 530 addressing complex science oriented issues in long term forest management plans. 
534 (Edwards and Hirsch 2012; Keenan 2015). Managing forests with new mandates and objectives,

535 new methods, and possibly more intensive management approaches will require increased

536 financial and human resources. Numerous authors have noted that limits on the financial

537 resources available for adaptation and mitigation represent a significant barrier (Innes et al. 2009;

538 Roberts et al. 2009; Seppälä et al. 2009; Johnston et al. 2010; Johnston and Hesseln 2012; Littell

539 et al. 2012; Rayner 2012; Guariguata et al. 2012; Hoberg et al. 2016; Lawrence 2017). Nelson et

540 al. (2016) similarly reported that, according to BC forest professionals, a general lack of capacity

541 and multiple competing demands on existing resources were significant barriers to climate

542 change adaptation. Johnston and Hesseln (2012) noted that managers in the Canadian forest

543 industry are concerned about economic issues and often they do not have sufficient time to

544 address longer-term issues such as climate change, even though they recognize its importance.

545 Although effective implementation of a comprehensive and integrated approach to

546 climate change in forest management is contingent on increased funding, recent evidence

547 suggests an opposing trend, with some forest management organizations and forestry companies

548 undergoing decreases in staff and budget (Johnston et al. 2010; Morgan and Daust 2013;

549 Lawrence 2017).

550 Assessment

551

552

An often-mentioned barrier to climate change adaptation in forestry is a lack of

553 investment in comprehensive science-based assessments (Johnston and Williamson 2007;

554 Williamson et al. 2012; Lemprière et al. 2013; Nelson et al. 2016). Assessments of the current

555 and potential future impacts of climate change are a required step in the adaptation process

556 (Johnston and Williamson 2007; Williamson et al. 2012; Le Goff and Bergeron 2014; Janowiak 
557 et al. 2014). However, Johnston and Edwards (2013) found that in Canada, climate change

558 vulnerability assessments are not mainstreamed into forest management decision-making.

559 Assessments of forest carbon, of the potential impacts of climate change on forest carbon, and of

560 the amounts of carbon within harvested wood products (along with product substitution effects)

561 are required for identification and implementation of mitigation measures (Nabuurs et al. 2007;

562 Lemprière et al. 2013; Smyth et al. 2014). However, there are currently limits on the ability to

563 model the impacts of climate change on forests (and therefore forest carbon) (Lemprière et al.

564 2008; Lempriere et al. 2017). Mainstreaming of adaptation and mitigation requires integrated

565 assessment approaches that evaluate climate change impacts (including impacts on forest

566 carbon); the effects of joint adaptation and mitigation strategies; and the relation of these

567 strategies to other forest management objectives. The knowledge, tools, methods, and data to

568 support these goals do not currently exist (Locatelli et al. 2011; Lempriere et al. 2017).

569 Monitoring

570 The incorporation of aspects of adaptive management and adaptive governance into decision-

571 making has been suggested as a way of responding to the increased uncertainty and variability of

572 impacts associated with climate change (Seppälä et al. 2009; West et al. 2009; Klenk et al. 2011;

573 FAO 2013; Millar et al. 2014; Keenan 2015; Lawrence 2017). Mainstreaming is often described

574 as a continuous process that incorporates adaptive management principles (Williamson et al.

575 2012). Adaptive management requires effective monitoring for early identification of impacts

576 (Spittlehouse 2005; Williamson et al. 2012; Janowiak et al. 2014). It also requires effective

577 monitoring to generate the knowledge and information necessary to evaluate previously

578 implemented adaptation and mitigation measures and to determine whether changes in direction

579 are required (Williamson et al. 2012). Some authors have suggested that current monitoring 
580 capacity is insufficient to support forest management under a changing climate (Spittlehouse

581 2005; Williamson et al. 2009; Metsaranta et al. 2011). BC forest professionals, for example,

582 perceived the current state of monitoring as a barrier to adaptation (Nelson et al. 2016).

583 Conclusions

584 The ability of Canadian forest managers to "incorporate climate change considerations into 585 all aspects of sustainable forest management" is an open question. We suggest, however, that 586 recent progress on adaptation and mitigation in Canadian forestry indicates that there is an 587 intrinsic capacity for modifying and improving forest management systems in response to new 588 drivers of change including climate change.

This study identifies and evaluates barriers to enhanced and integrated climate change

590 adaptation and mitigation in Canadian forest management. A number of harmonization, enabling, 591 and implementation related barriers are identified. Barriers are structural, interrelated, and 592 dynamic. Overcoming barriers will involve continuation of the complex and incremental process 593 of learning, policy development, and transformation that is already underway in Canadian 594 forestry relative to climate change. An important question is: What is a logical next step relative 595 to dealing with barriers to comprehensive and integrated adaptation/mitigation? We propose that 596 a significant early requirement is to address harmonization barriers because as long as there are 597 substantive differences in frames and beliefs about adaptation and mitigation there will be 598 ambivalence or opposition to even initial consideration of integrated approaches. As noted in this 599 manuscript one strategy for addressing harmonization barriers would be to advance research and 600 analysis of joint adaptation/mitigation strategies. Also as Locatelli et al. (2011) suggest processes

601 that allow mitigation experts to become better informed about adaptation and vise versa would 602 improve prospects for integration. 
A number of potential research questions emerge from this review. The barriers identified in

604 this manuscript are considerable. Institutional and governance related barriers are particularly

605 challenging to overcome. Our understanding of policy and decision-making processes in forest

606 management and how these processes affect the capacity to implement comprehensive and

607 integrated approaches to climate change in forest management is a knowledge gap (Klenk et al.

608 2011). Another research opportunity is to undertake more in-depth research into the

609 interrelationships and dynamic nature of the barriers identified in this study (Eisenack et al.

610 2014) and to investigate how and why barriers emerge and persist (Biesbroek et al. 2013). This

611 knowledge would inform political/policy change and would help in developing intervention

612 strategies. Empirical studies identifying and assessing barriers and interventions to overcome

613 barriers in specific contexts would contribute to a better understanding of change processes in

614 forest management.

\section{Acknowledgments}

616 We thank Tony Lempriere (Natural Resources Canada), Mark Johnston (Saskatchewan Research

617 Council) and Jason Edwards (Natural Resources Canada) for providing many insightful technical

618 comments on an earlier draft of this manuscript. We also thank and acknowledge Brenda

619 Laishley and Peggy Robinson for their considerable contributions in editing and enhancing the 620 quality and readability of this manuscript.

621

622 
623

624 625

626

627

628

629

630

631

632

633

634

635

636

637

638

639

640

641

644 645 642 R., Buck, A., Katila, P. (Eds.), Adaptation of Forests and People to Climate Change. A Global 643 Assessment Report. IUFRO World Ser. Vol. 22. International Union of Forest Research

\section{References}

Berry, P.B., Brown, S., Chen, M., Kontogianni, A., Rowlands, O., Simpson, G., and Skourtos, M. 2015. Cross-sectoral interactions of adaptation and mitigation measures. Clim. Change 128: 281-393.

Bennett, C.J., and Howlett, M. 1992. The lessons of learning: Reconciling theories of policy learning and policy change. Policy Sciences. 25(3):275-294

Biesbroek, G.R., Swart, R.J., and van der Knapp, W.G.M. 2009. The mitigation-adaptation dichotomy and the role of spatial planning. Habitat Int. 33: 230-237.

Biesbroek, G.R., Klostermann, J.E., Termeer, C.J.A.M., Kabut, P. 2013. On the nature of barriers to climate change adaptation. Reg. Environ. Change 13: 1119-1129.

Blades, J.J., Klos, P.Z., Kemp, K.B., Hall, T.E., Force, J.E., Morgan, P., and Tinkham, W.T. 2016. Forest manager's response to climate change science: evaluating the constructs of boundary objects and organizations. For. Ecol. Manage. 360: 376-387.

41 Buck, A., Katila, P., and Seppälä, R. 2009. Main conclusions and the way forward. In Seppälä, Organizations, Helsinki, Finland, pp. 211-212. 
646 [CCFM] Canadian Council of Forest Ministers. 2008. A vision for Canada's forests: 2008 and 647 beyond. CCFM, Ottawa, ON. http://www.ccfm.org/pdf/Vision EN.pdf (accessed September 3, 648 2017).

649

650 [CCFM] Canadian Council of Forest Ministers. 2009. A Framework for Forest Management

651 Offset Protocols. CCFM, Ottawa, ON. http://www.ccfm.org/english/coreproducts-cc.asp 652 (accessed June 22, 2017).

653

654 Carlson, M., Chen, J., Elgie, S., Henschel, C., Montenegro, A., Roulet, N., Scott, N., Tarnocai, 655 C., and Wells, J. 2010. Maintaining the role of Canada's forests and peatlands in climate 656 regulation. The For. Chron. 86(4): 434-443.

657

658 Collaborative Partnership on Forests. 2008. Strategic Framework for Forests and Climate 659 Change. http://www.fao.org/climatechange/16610-021c3e37e948779fd106efb93e9f5cc58.pdf 660 (accessed September 3, 2017).

661

662 Colombo, S.J. 2006. How OMNR Staff Perceive Risks Related to Climate Change and Forests. 663 Ont. Minist. Nat. Resour., Ont. For. Res. Inst., For. Res. Inf. Paper No. 143. Queen's Printer for 664 Ontario, Toronto, ON.

665

666 Cowling, R.M., Egoh, B., Knight, A.T., O’Farrell, P.J., Reyers, B., Rouget, M., Roux, D.J., 667 Welz, A., and Wilhelm-Rechman, A. 2008. An operational model for mainstreaming ecosystem 668 services for implementation. Proc. Natl. Acad. Sci. 105: 9843-9488. 
670 Colombo, S.J., Chen, J., Ter-Mikaelian, M.T., McKechnie, J., Elkie, P.C., MacLean, H.L., and

671 Heath, L.S. 2012. Forest protection and forest harvest as strategies for ecological sustainability

672 and climate change mitigation. For. Ecol. Management. 281: 140-151.

673

674 D”Amato, A.W., Bradford, J.B., Fraver, S., and Palik, B.J. 2011. Forest management for

675 mitigation and adaptation to climate change: insights from long-term silviculture experiments.

676 For Ecol Manag. 262: 803-816.

677

678 Davidson, D.J., Williamson, T., and Parkins, J.R. 2003. Understanding climate change risk and

679 vulnerability in northern forest-based communities. Can. J. For. Res. 33: 2252-2261.

680

681 Duguma, L.A., Minang, P.A., and Noordwijk, M.V. 2014. Climate change mitigation and

682 adaptation in the land use sector: from complementarity to synergy. Environ. Manage. 54: 420-

$683 \quad 432$.

684

685 Edwards, J.E., and Hirsch, K.G. 2012. Adapting Sustainable Forest Management to Climate

686 Change: Preparing for the Future. Can. Counc, For. Minist., Clim. Change Task Force, Ottawa,

687 ON. http://www.ccfm.org/english/index.asp (accessed June 22, 2017). 
689 Edwards, J.E., Pearce, C., Ogden, A.E., and Williamson, T.B. 2015. Climate Change and 690 Sustainable Forest Management in Canada: A Guidebook for Assessing Vulnerability and 691 Mainstreaming Adaptation into Decision Making. Can. Counc, For. Minist., Clim. Change Task 692 Force, Ottawa, ON. http://www.ccfm.org/english/index.asp -(accessed June 22, 2017).

693

694 Eisenack, K., Moser, S.C., Hoffmann, E., Klein, R.J.T., Oberlack, C., Pechan, A., Rotter, M., and 695 Termeer, C.J.A.M. 2014. Explaining and overcoming barriers to climate change adaptation. 696 Nature Clim. Change 4: 867-872.

[FAO] Food and Agriculture Organization. 2013. Climate change guidelines for forest managers. 699 FAO For. Pap. 172. FAO, Rome, Italy.

Ford, J.D., Berrang-Ford, L., and Paterson, J. 2011. A systematic review of observed climate 705 change adaptation in developed nations. Clim. Change 106: 327-336.

707 Ford, J.D., and King, D. 2015. A framework for examining adaptation readiness. Mitig. Adapt.

708 Strat. Glob. Change 20: 505-526. 
710 Fussel, H.M., and Klein, R.T. 2006. Climate change vulnerability assessments: an evolution of 711 conceptual thinking. Clim. Change 75: 301-329.

712

713 Gauthier, S., Bernier, P., Burton, P.J., Edwards, J., Isaac, K., Isabel, N., Jayen, K., Le Goff, H., 714 and Nelson, E.A. 2014. Climate change vulnerability and adaptation in the managed Canadian 715 boreal forest. Environ. Rev. 22: 256-285.

716

717 Golden, D.M., Smith, M.A., and Colombo, S.J. 2011. Forest carbon management and carbon 718 trading. A review of Canadian forest options for climate change mitigation. The For. Chron. 719 87(5): 625-635.

720

721 Gray, P. 2012. Adapting Sustainable Forest Management to Climate Change: A Systematic 722 Approach for Exploring Organizational Readiness. Can. Counc, For. Minist., Clim. Change Task 723 Force, Ottawa, ON. http://www.ccfm.org/english/coreproducts-cc.asp (accessed June 22, 2017) 724

725 Greig, M., and Bull, G. 2011. Carbon management in British Columbia's forests: an update on 726 opportunities and challenges. BC Journal of Ecosystems and Management. 12(3): 35-54.

727

728 Guariguata, M.R., Cornelius, J.P., Locatelli, B., Forner, C., and Sanchez-Azofeifa, G.A. 2008.

729 Mitigation needs adaptation: tropical forestry and climate change. Mitig. Adapt. Strat. Glob.

730 Change 13: 793-808. 
733 Guariguata, M.R., Locatelli, B., and Haupt, F. 2012. Adapting tropical production forests to 734 global climate change: risk perceptions and actions. Int. For. Rev. 14(1): 27-38.

735

736 Hoberg, G., Peterson St-Laurent, G., Schittecatte, G., and Dymond, C.C. 2016. Forest carbon 737 mitigation policy: a policy gap analysis for British Columbia. For. Policy Econ. 69: 73-82.

Hotte, N., Mahony, C., and Nelson, H. 2016. The principal-agent problem and climate change 740 adaptation on public lands. Glob. Environ. Change 36: 163-174.

741

Innes, J., Joyce, L., Kellomaki, S., Louman, B., Ogden, A., Parrotta, J., and Thompson, I. 2009.

743 Management for adaptation, in: Seppälä, R., Buck, A., Katila, P. (Eds.), Adaptation of Forests

744 and People to Climate Change. A Global Assessment Report. IUFRO World Ser. Vol. 22.

745 International Union of Forest Research Organizations, Helsinki, Finland, pp. 135-186.

746

747 Janowiak, M.K., Swantson, C.W., Nagel, L.M., Brandt, L.A., Butler, P.R., Handler, S.D., 748 Shannon, P.D., Iverson, L.R., Matthews, S.N., Prasad, A., and Peters, M.P. 2014. A practical 749 approach for translating climate change adaptation principles into forest management actions. J. 750 For. 112: 424-433.

751

752 Jantarasami, L.C., Lawler, J.J., and Thomas, C.W. 2010. Institutional barriers to climate change 753 adaptation in U.S. national parks and forests. Ecol. Soc. 15(4): 33. 
755 Johnston, M., and Williamson, T. 2007. A framework for assessing climate change vulnerability 756 of the Canadian forest sector. For. Chron. 83: 358-361.

757

758 Johnston, M., Campagna, M., Gray, P., Kope, H., Loo, J., Ogden, A., O’Neil, G.A., Price, D., 759 and Williamson, T. 2009. Vulnerability of Canada's Tree Species to Climate Change and 760 Management Options for Adaptation. Can. Counc. For. Minist., Clim. Change Task Force, 761 Ottawa, ON. http://www.ccfm.org/english/coreproducts-cc.asp (accessed June 22, 2017)

762

763 Johnston, M., Williamson, T., Munson, A., Ogden, A., Moroni, M., Parson, R., Price, D., and 764 Stadt, J. 2010. Climate change and forest management in Canada: impacts, adaptive capacity, 765 and adaptation options. A state of knowledge report. Univ. Alta., Sustain. For. Manage. Netw., 766 Edmonton, AB.

767

768 Johnston, M., and Hesseln, H. 2012. Climate change adaptive capacity of the Canadian forest 769 sector. For. Policy Econ. 24: 29-34.

770

771 Johnston, M., and Edwards, J. 2013. Adapting Sustainable Forest Management to Climate 772 Change: An Analysis of Canadian Case Studies. Can. Counc. For. Minist., Clim. Change Task 773 Force, Ottawa, ON. http://www.ccfm.org/english/coreproducts-cc.asp (Accessed June 22, 2017)

774

775 Joyce, L.A., Blate, G.M., McNulty, S.G., Millar, C.I., Moser, S., Neilson, R.P., and Peterson, 776 D.L. 2009. Managing for multiple resource under climate change: national forests. Environ.

777 Manage. 44: 1022-1032. 
779 Kahneman, D., and Tversky, A. 1982. The psychology of preference. Sci. Am. 246: 160-173.

780

781 Kahneman, D., Knetsch, J.L., and Thaler, R.H. 1991. Anomalies: the endowment effect, loss

782 aversion, and status quo bias. J. Econ. Perspect. 5: 193-206.

783

784 Kant, P., and Wu, S. 2012. Should adaptation to climate change be given priority over mitigation 785 in tropical forests? Carbon Manage. 3: 303-311.

786

787 Kates, R.W., Travis, W.R., and Wilbanks, T.J. 2012. Transformational adaptation when

788 incremental adaptations t oclimate change are insufficient. PNAS. 109(19): 7156-7161.

789

790 Keenan, R.J. 2015. Climate change impacts and adaptation in forest management: a review. Ann.

791 For. Sci. 72: 145-167.

792

793 Keenan, R.J. 2016. Forests and climate change: introduction to a special section. For. Ecol.

794 Manage. 360: 353-356.

795

796 Kennedy, M.I.L., Lantz, V.A., and MacLean, D.A. 2007. Forest and economic impacts of

797 alternative management strategies on crown land in New Brunswick. Can. J. For. Res. 37: 2624-

7982636.

799 
800 Keskitalo, E.C.H. 2011. How can forest management adapt to climate change? Possibilities in

801 different forestry systems. Forests 2: 415-430.

802

803 Klein, R.J.T., Schipper, E.L.F., and Dessai, S. 2005. Integrating mitigation and adaptation into

804 climate and development policy: three research questions. Environ. Sci. Policy 8: 579-588.

805

806 Klenk, N.L., Adams, B.W., Bull, G.Q., Innes, J.L., Cohen, S.J., and Larson, B.C. 2011. Climate

807 change adaptation and sustainable forest management: a proposed reflexive research agenda.

808 For. Chron. 87: 351-357.

809

810 Klenk, N.L., Larson B.M.H., and McDermott, C. 2015. Adapting forest certification to climate

811 change. Wiley Interdiscip. Rev. Clim. Change 6: 189-201.

812

813 Lawrence, A. 2017. Adapting through practice: silviculture, innovation, and forest governance

814 for the age of extreme uncertainty. For. Policy Econ. 79: 50-60.

815

816 Le Goff, H., and Bergeron Y. 2014. Vulnerability assessment to climate change of three

817 ecosystem-based forest management projects in Quebec. The Forestry Chronicle. 90(2): 214-

818227.

819

820

821 
822 Lemprière, T.C., Bernier, P.Y., Carroll, A.L., Flannigan, M.D., Gilsenan, R.P., McKenney,

823 D.W., Hogg, E.H., Pedlar, J.H., and Blain, D. 2008. The importance of forest sector adaptation to

824 climate change. Nat. Resour. Can., Can. For. Serv., North. For. Cent., Edmonton, AB. Inf. Rep.

825 NOR-X-416E.

826

827 Lemprière, T.C., Kurtz, W.A., Hogg, E.H., Schmoll, C., Rampley, G.J., Yemshanov, D.,

828 McKenney, D.W., Gilsenan, R., Beatch, A., Blain, D., Bhatti, J.S., and Krcmar, E. 2013.

829 Canadian boreal forests and climate change mitigation. Environ. Rev. 21: 293-321.

830

831 Lempriere, T.C., Krcmar, E., Rampley, .G.J., Beatch, A., Smyth, C.E., Hafer, M., and Kurz,

832 W.A. 2017. Cost of climate change mitigation in Canada's forest sector. Can. J. For. Res. 47:

$833 \quad 604-614$.

834

835 Lindahl, K.B.; Sandstrom, C.; Stens, A. 2017. Alternative pathways to sustainability? Comparing

836 forest governance models. For. Pol. Econ. 77: 69-78.

837

838 Littell, J.S., Peterson, D.L., Millar, C.I., O’Halloran, K.A.O. 2012. U.S. national forests adapt to

839 climate change through science-management partnerships. Clim. Change 110: 269-296.

840

841 Locatelli, B., Evans, V., Wardell, A., Andrade, A., and Vignola, R. 2011. Forests and climate

842 change in Latin America: linking adaptation and mitigation. Forests 2: 431-450. 
844 Locatelli, B., Pavegeau, C., Pramova, E., and Di Gregorio, M. 2015. Integrating climate change 845 mitigation and adaptation in agriculture and forestry: opportunities and trade-offs. Wiley 846 Interdiscip. Rev. Clim. Change 6: 585-598.

847

848 Man, C.D., Lyons, K.C., Nelson, J.D., and Bull, J.Q. 2015. Costs to produce carbon credits by 849 reducing the harvest level in British Columbia, Canada. For. Pol. Econ. 52: 9-17.

850

851 McKenney, D., Yemshanov, D., Fox, G. and Ramial, E. 2004. Cost estimates for carbon 852 sequestration from fast growing poplar plantation in Canada. For. Pol. Econ 6(3-4): 345-358.

853

854 Metsaranta, J.H., Dymond, C.C., Kurz, W.A., and Spittlehouse, D.L. 2011. Uncertainty of 21 st 855 century growing stocks and GHG balance of forests in British Columbia, Canada resulting from 856 potential climate change impacts on ecosystem processes. For. Ecol. Manag. 262: 827-837.

858 Millar, C., Stephenson, N.L., and Stephens, S.L. 2007. Climate change and forests of the future: 859 managing in the face of uncertainty. Ecol. Appl. 17: 2145-2151.

860

861 Millar, C.I., Swanston, C.W., and Peterson, D.L. 2014. Adapting to climate change, in: Peterson, 862 D.L., Vose, J.M., Patel-Weynand, T. (Eds.), 2014. Climate Change and United States Forests.

863 Springer, New York, pp. 183-222. 
865 Morgan, D., and Daust, D. (Eds.) 2013. A Climate Change Vulnerability Assessment for British

866 Columbia’s Managed Forests. Government of British Columbia, Victoria, BC.

868 Morin, M.B., Kneeshaw, D., Doyon, F., Le Goff, H., Bernier, P., Yelle, V., Blondlot, A., and 869 Houle, D. 2015. Climate change and the forest sector: Perception of principal impacts and of 870 potential options for adaptation. The For. Chron. 91(4): 395-406

871

872 Moser, S., and Ekstrom, J. 2010. A framework to diagnose barriers to climate change adaptation.

873 Proc. Natl. Acad. Sci. 107: 22026-22031.

875 Moser, S. 2012. Adapation, mitigation, and their disharmonious discontents: an essay. Clim.

876 Change 111: 165-175.

878 Nabuurs, G.J., Masera, O., Andrasko, K., Benitez-Ponce, P., Boer, R., Dutschke, M., Elsiddig,

879 E., Ford-Robertson, J., Frumhoff, P., Karjalainen, T., Krankina, O., Kurz, W.A., Matsumoto,

880 M., Oyhantcabal, W., Ravindranath, N.H., Sanz Sanchez, M.J., and Zhang, X. 2007. Forestry, in:

881 Metz, B., Davidson, O.R., Bosch, P.R., Dave, R., Meyer, L.A. (Eds.), Climate Change 2007:

882 Mitigation. Contribution of Working Group III to the Fourth Assessment Report of the

883 Intergovernmental Panel on Climate Change. Cambridge Univ. Press, Cambridge, UK. 
885 Nelson, H., Williamson, T., Macaulay, C., and Mahony, C. 2016. Assessing the potential for 886 forest management practitioner participation in climate change adaptation. For. Ecol. Manage.

887 360: $388-399$.

888

889 Nitschke, C.R., and Innes, J.L. 2008. Integrating climate change into forest management in 890 South-Central British Columbia: an assessment of landscape vulnerability and development of a 891 climate-smart framework. For. Ecol. Manage. 256: 313-327.

892

893 Norman, B. 2008. Principles for an intergovernmental agreement for coastal planning and 894 climate change in Australia. Habitat Int. 33: 293-299.

895

896 Ogden, A.E., and Innes, J. 2007a. Incorporating climate change adaptation considerations into 897 forest management planning in the boreal forest. Int. For. Rev. 9: 713-733.

898

899 Ogden, A.E., and Innes, J. 2007b. Perspectives of forest practitioners on climate change 900 adaptation in the Yukon and Northwest Territories of Canada. For. Chron. 83: 557-569.

901

902 Ogden, A.E., and Innes, J.L. 2009. Application of structured decision making to an assessment of 903 climate change vulnerability and adaptation options for sustainable forest management. Ecol. 904 Soc. 14(1): 11. 
927 Prescott, C.E., and Weese, K. 2014. Crossing the divide: engaging scientists and policy-makers 928 in adapting forest management to climate change in British Columbia. For. Chron. 90: 89-95.

Ohlson, D.W., McKinnon, G.A., and Hirsch, K.G. 2005. A structured decision-making approach to climate change adaptation in the forest sector. The For. Chron. 81(1): 97-103.

Pahl Wostl, C.L. 2009. A conceptual framework for analysing adaptive capacity and multi-level learning processes in resource governance regimes. Glob. Environ. Change 19: 354-365.

Pasquini, L., Ziervogel, G., Cowling, R.M., and Shearing, C. 2015. What enables local governments to mainstream climate change adaptation? Lessons learned from two municipal case studies in the Western Cape, South Africa. Climate and Development. 7(1):60-=70.

Peterson, D.L., Millar, C.I., Joyce, L.A., Furniss, M.J., Halofsky, J.E., Neilson, R.P., and Morelli, T.L. 2011. Responding to climate change in national forests: a guidebook for developing adaptation options. Gen. Tech. Rep. PNW-GTR_855. U.S. Dep. Agric., For. Serv., Pac. Northwest Res. Stn., Portland, OR. 109 p.

Peterson, D.L., Vose, J.M., and Patel-Weynand, T. (Eds.). 2014. Climate Change and United States Forests. Springer, New York.

Pettersson, M., and Keskitalo, E.C. 2013. Adaptive capacity of legal and policy frameworks for biodiversity protection considering climate change. Land Use Policy 34: 213-222. 
Price, D. T.; Alfaro, R.I.; Brown, K.J.; Flannigan, M.D.; Fleming, R.A.; Hogg, E.H.; Girardin,

931

932

933

934

935

936

937

938

939

940

941

942

943

944

945

947 Uncertain. 1: 7-59.

946 Samuelson, W., and Zeckhauser, R.J. 1988. Status quo bias in decision making. J. Risk

M.P.; Lakusta, T.; Johnston, M.; McKenney, D.W.; Pedlar, J.H.; Stratton, T.; Sturrock, R.N.;

Thompson, I.D.; Trofymow, J.A.; and Venier, L.A. 2013. Anticipating the consequences of

climate change for Canada's boreal forest ecosystems. Environ. Rev. 21: 322-365.

Ravindranath, N.H. 2007. Mitigation and adaptation synergy in forest sector. Mitig. Adapt. Strat.

Glob. Change. 12: 843-853.

Rayner, J. 2012. Shifting mandates and climate change policy capacity: the forestry case. Can.

Polit. Sci. Rev. 6: 75-85.

Roberts, G., Parrotta, J., and Wreford, A. 2009. Current adaptation measures and policies, in:

Seppälä, R., Buck, A., Katila, P. (Eds.), 2009. Adaptation of Forests and People to Climate

Change. A Global Assessment Report. IUFRO World Ser. Vol. 22. International Union of Forest

Research Organizations, Helsinki, Finland, pp. 123-134.

948

949 Sedjo, R., and Solomon, A. 1989. Greenhouse warming: abatement and adaptation, in: Crosson,

950 P., Darmstadter, J., Easterling, W., and Rosenberg, N. (Eds.), Resources for the Future.

951 Proceedings, July 1989, pp. 110-119. Resources for the Future, Washington, DC. 
953 Seppälä, R., Buck, A., and Katila, P. (Eds.). 2009. Adaptation of Forests and People to Climate

954 Change. A Global Assessment Report. IUFRO World Ser. Vol. 22. International Union of Forest

955 Research Organizations, Helsinki, Finland.

956

957 Smith, P., Bustamante, M., Ahammad, H., Clark, H., Dong, H., Elsiddig, E.A., Haberl, H., 958 Harper, R., House, J., Jafari, M., Masera, O., Mbow, C., Ravindranath, N.H., Rice, C.., Robledo 959 Abad, C., Romanovskaya, A., Sperling, F., and Tubiello, F. 2014. Agriculture, forestry and other 960 land use (AFOLU), in: Edenhofer, O., Pichs-Madruga, R., Sokona, Y., Farahani, E., Kadner, S., 961 Seyboth, K., Adler, A., Baum, I., Brunner, S., Eickemeier, P., Kriemann, B., Savolainen, J., 962 Schlömer, S., von Stechow, C., Zwickel, T., and Minx, J.C. (Eds.), Climate Change 2014:

963 Mitigation of Climate Change. Contribution of Working Group III to the Fifth Assessment 964 Report of the Intergovernmental Panel on Climate Change. Cambridge Univ. Press, Cambridge, 965 UK, pp. 811-922.

966

967 Smyth, C.E., Stinson, G., Neilson, E., Lemprière, T.C., Hafer, M., Rampley, G.J., and Kurz, 968 W.A. 2014. Quantifying the biophysical climate change mitigation potential of Canada's forest 969 sector. Biogeosci. Discuss. 11: 441-480.

970

971 Spittlehouse, D.L. 2005. Integrating climate change adaptation into forest management. For.

972 Chron. 81: 691-695.

973 
974 Steenberg, J.W.M., Duinker, P.N., Van Damme, L., and Zielke, K. 2013. Criteria and indicators

975 of sustainable forest management in a changing climate: an evaluation of Canada's national

976 framework. J. Sustain. Dev. 6: 32-64.

977

978 Thuy, P.T., Moeliono, M., Locatelli, B., Brockhaus, M., Di Gregorio, M.D., and Mardiah, S.

979 2014. Integration of adaptation and mitigation in climate change and forest policies in Indonesia 980 and Vietnam. Forests 5: 2016-2036.

981

982 Timberlake, T.J. and Schultz, C.A. 2017. Policy, practice, and partnerships for climate change 983 adaptation on US national forests. Climatic Change. 144(2):257-269.

984

985

Tol, R.S.J. 2005. Adaptation and mitigation: trade-offs in substance and methods. Environ. Sci.

986 Policy 8: 572-578.

987

988

Van Damme, L., Duinker, P.N., and Quintilio, D. 2008. Embedding science and innovation in

989 forest management: Recent experiences at Millar Western in west-central Alberta. The For.

990 Chron. 84(3): 301-306.

991

992 Wamsler, C. 2015. Mainstreaming ecosystem-based adaptation: transformation toward

993 sustainability in urban governance and planning. Ecol and Soc. 220(2):30.

994

995 Wang, W., and McCarl, B.A. 2013. Temporal investment in climate change adaptation and

996 mitigation. Clim. Change Econ. 4: 1-18. 
998 West, J.M., Julius, S.H., Kareiva, P., Enquist, C., Lawler, J.J., Petersen, B., Johnson, A.E., and 999 Shaw, M.R. 2009. U.S. natural resources and climate change: concepts and approaches for 1000 management adaptation. Environ. Manage. 44: 1001-1021.

1001

1002 Williamson, T.B., Parkins, J.R., and McFarlane, B.L. 2005. Perceptions of climate change risk to 1003 forest ecosystem and forest-based communities. For. Chron. 81: 710-716.

1004

1005 Williamson, T.B., Colombo, S.J., Duinker, P.N., Gray, P.A., Hennessey, R.J., Houle, D., 1006 Johnson, M.H., Ogden, A.E., and Spittlehouse, D.L. 2009. Climate Change and Canada's 1007 Forests: From Impacts to Adaptation. Univ. Alta., Sustain. For. Manage. Netw.; Nat. Resour. 1008 Can., Can. For. Serv., North. For. Cent., Edmonton, AB.

Williamson, T.B., Campagna, M.A., and Ogden, A.E. 2012. Adapting Sustainable Forest Management to Climate Change: A Framework for Assessing Vulnerability and Mainstreaming 1012 Adaptation into Decision Making. Can. Counc. For. Minist., Clim. Change Task Force, Ottawa, 1013 ON. http://www.ccfm.org/english/coreproducts-cc.asp (accessed June 22, 2017)

1015 Williamson, T.B., and Isaac, K.J. 2013. Adapting Sustainable Forest Management to Climate 1016 Change: An Overview of Approaches for Assessing Human Adaptive Capacity. Can. Counc. 1017 For. Minist., Clim. Change Task Force, Ottawa, ON. http://www.ccfm.org/english/coreproducts1018 cc.asp (accessed June 22, 2017) 
1020 Williamson, T.B., and Edwards, J.E. 2014. Adapting Sustainable Forest Management to Climate 1021 Change: Criteria and Indicators in a Changing Climate. Can. Counc. For. Minist., Clim. Change 1022 Task Force, Ottawa, ON. http://www.ccfm.org/english/coreproducts-cc.asp (accessed June 22, 1023 2017).

1024

1025 Xu, Z., Smyth, C.E., Lempriere, T.C., Rampley, G.J., Kurz, W.A. 2017. Climate change

1026 mitigation strategies in the forest sector: Biophysical impacts and economic implications in

1027 British Columbia, Canada. Mitig Adapt Strateg Glob Change. DOI 10.1007/s11027-016-9735-7

1028

1029

1030 
Table 1. Barriers to integrated consideration of adaptation and mitigation in forest management

Category Barriers

Harmonization

Differences between A and $\mathrm{M}$ in knowledge and understanding of each domain by agents

Differences in beliefs and framing about $\mathrm{A}$ and $\mathrm{M}$

Enabling Psychological factors: e.g., cognitive bias, perception bias

Lack of leadership and political will to proceed with enhanced and integrated $\mathrm{A}$ and $\mathrm{M}$

Institutions that do not enable enhanced and integrated $\mathrm{A}$ and $\mathrm{M}$

Implementation Governance systems that do not support enhanced and integrated A and M

Insufficient or ineffective investment in science and knowledge relative to A and $\mathrm{M}$ mainstreaming requirements

Underinvestment in knowledge exchange, education, and training

Insufficient funding for enhanced and integrated $\mathrm{A}$ and $\mathrm{M}$ mainstreaming

Insufficient assessment capacity to support mainstreaming

Insufficient monitoring capacity

Table 2. Initiatives in Canadian forest management to raise awareness about climate change 
impacts and adaptation

- $\quad$ Efforts by various Canadian Model Forests,

- Collaborative work by provinces and the federal government through the Canadian Council of Forest Ministers,

- $\quad$ Outreach and knowledge exchange activities by provincial management agencies,

- Work by the Canadian Federal Government through the now disbanded Canadian Climate Impacts and Adaptation Research Network (CCIARN) and more recently through various adaptation platforms,

- National and regional assessments,

- Knowledge exchange activities conducted by professional forester organizations (e.g., The Association of British Columbia Forest Professionals), work conducted by the Canadian Forestry Community of Practice (FACOP), and the Canadian Institute of Forestry

- Work conducted by industry associations such as the Forest Products Association of Canada

- Work completed by the now disbanded Network Centre of Excellence on Sustainable Forest Management. 